\title{
Role of endoplasmic reticulum stress in apoptosis of differentiated mouse podocytes induced by high glucose
}

\author{
YANPING CAO ${ }^{1,2^{*}}$, YONGMEI HAO ${ }^{3 *}, \mathrm{HANG} \mathrm{LI}^{4}$, QINGJUAN LIU ${ }^{1}$, \\ FENG GAO ${ }^{5}$, WEI LIU ${ }^{1}$ and HUIJUN DUAN ${ }^{1}$ \\ ${ }^{1}$ Department of Pathology, Hebei Medical University, Shijiazhuang, Hebei 050017; ${ }^{2}$ Department of Nephrology, \\ The First Hospital of Handan, Handan, Hebei 056002; ${ }^{3}$ Department of Endocrinology, \\ The Second Hospital of Hebei Medical University, Shijiazhuang, Hebei 050000; \\ ${ }^{4}$ Department of Histology and Embryology, Hebei Medical University, Shijiazhuang, Hebei 050017; \\ ${ }^{5}$ Department of Pathology, The Third Hospital, Hebei Medical University, Shijiazhuang, Hebei 050051, P.R. China
}

Received October 12, 2013; Accepted January 22, 2014

DOI: $10.3892 / \mathrm{ijmm} .2014 .1642$

\begin{abstract}
Podocytes are terminally differentiated epithelial cells lacking the ability to proliferate. The loss of podocytes is a hallmark of progressive kidney diseases, including diabetic nephropathy (DN). Endoplasmic reticulum stress (ERS)induced apoptosis is involved in a number of pathological conditions, including DN. The aim of the present study was to investigate whether a high glucose environment induces the apoptosis of podocytes through ERS. Differentiated mouse podocytes were divided into three groups: the normal glucose group (NG, $1 \mathrm{~g} / 1 \mathrm{D}$-glucose), the high glucose group (HG, $4.5 \mathrm{~g} / 1 \mathrm{D}$-glucose) and the mannitol group (M, $1 \mathrm{~g} / \mathrm{l} \mathrm{D}$-glucose plus $24.4 \mathrm{mM}$ mannitol). The cells were harvested following stimulation with the indicated treatments for 12, 24, 48 and $72 \mathrm{~h}$. Podocyte apoptosis was determined using TUNEL assay and flow cytometry (propidium iodide staining). Glucoseregulated protein 78 (GRP78), CCAAT/enhancer-binding protein $(\mathrm{C} / \mathrm{EBP})$ homologous protein $(\mathrm{CHOP} / \mathrm{GADD} 153)$ and caspase-12 expression was analyzed by RT-PCR, western blot analysis and immunocytochemistry. The apoptotic rate increased significantly in the HG group compared with the NG and $\mathrm{M}$ groups at 48 and $72 \mathrm{~h}$ (all $\mathrm{P}<0.01)$. GRP78 expression, an indicator of ERS, was increased from $12 \mathrm{~h}$, indicating that ERS was activated. Subsequently, two ER-associated death (ERAD) pathways, the CHOP/GADD153- and caspase-12-dependent
\end{abstract}

Correspondence to: Dr Huijun Duan, Department of Pathology, Hebei Medical University, 361 Zhongshan East Road, Shijiazhuang, Hebei 050017, P.R. China

E-mail: duanhj999@163.com

*Contributed equally

Key words: endoplasmic reticulum stress, unfolded protein response, podocytes, apoptosis, diabetic nephropathy pathways, were detected. CHOP/GADD153 expression reached its peak at $48 \mathrm{~h}$, and caspase-12 expression gradually increased with time. Spearman's correlation analysis revealed that caspase-12 and CHOP/GADD153 positively correlated with the apoptotic rate $(\mathrm{r}=0.915, \mathrm{P}<0.01$ and $\mathrm{r}=0.639, \mathrm{P}<0.01)$. Our results demonstrated that hyperglycemia (high glucose) induced apoptosis partly through ERS in the differentiated mouse podocytes, which possibly contributes to the pathogenesis of DN.

\section{Introduction}

Diabetic nephropathy (DN) is one of the most common microvascular chronic complications associated with diabetes, and is the most common cause of end-stage renal disease $(1,2)$. DN develops over several years, and involves characteristic pathological changes, such as the excessive accumulation of extracellular matrix (ECM), glomerulosclerosis, tubule dilatation and atrophy, as well as interstitial fibrosis (3). Previous studies have focused on the accumulation of the ECM (4). A growing body of evidence suggests that glomerular podocytes are key players in DN (5). Podocytes are terminally differentiated cells unable to regenerate and the loss of podocytes results in permanent alterations in the glomerular filtration barrier (6,7).

The endoplasmic reticulum (ER) plays a critical role in controlling the fate of cells. The ER is a highly dynamic organelle responsible for multiple cellular functions. However, the ER is highly sensitive to alterations in its homeostasis. A number of conditions can disturb ER functions, and these conditions induce a state known as ER stress (ERS) $(8,9)$.

The hyperglycemia-induced increase in reactive oxygen species (ROS) has been shown to be involved in podocyte apoptosis and depletion in vitro and in vivo, suggesting that podocyte apoptosis/depletion represents a novel early mechanism leading to DN $(10,11)$. There are direct correlations between ERS and oxidative stress (12). Accumulating evidence indicates that ERS-related apoptosis may be involved in $\beta$-cell loss in type 1 and 2 diabetes mellitus $(13,14)$. 
A number of signaling pathways have evolved to cope with ERS. The first response involved is the unfolded protein response (UPR), in which ER chaperone proteins are upregulated, which may alleviate ERS (15). Glucose-regulated protein 78 (GRP78) is the main modulator of UPR. It can bind to ER sensors, such as protein kinase R (PKR)-like ER kinase, inositol requiring 1 (IRE1) and activating transcription factor 6 (ATF6), inhibiting their activation (16). GRP78 plays a critical role in the recognition of unfolded proteins (16).

If these adaptive responses cannot alleviate ERS, apoptosis is triggered by various pathways that are not yet fully understood. However, two pathways of ER-associated death (ERAD) have been defined, characterized by the activation of CCAAT/enhancer-binding protein (C/EBP) homologous protein $(\mathrm{CHOP} / \mathrm{GADD} 153)$ and of caspase-12 $(8,17)$.

However, the molecular mechanisms underlying the development of DN remain to be clarified. We hypothesized that ERS is involved in high glucose $(\mathrm{HG})$-induced podocyte apoptosis. The aim of this study was to examine the expression of GRP78 and the ERAD pathways (CHOP/GADD153- and caspase-12-dependent pathways) in podocytes exposed to a HG environment. The results revealed that podocytes treated with HG underwent ERS, which presumably is an adaptive, protective UPR reaction for cell survival; however, this protective effect was short-lived, since the continued exposure to HG eventually overpowered this protective effect, leading to apoptosis. These results indicate that novel (previously unkown) mechanisms involved in DN may be targeted by novel therapeutic interventions.

\section{Materials and methods}

Podocyte culture. Conditionally immortalized mouse podocytes purchased from the Cell Culture Center (Peking Union Medical College, Beijing, China) were cultured as previously described (6). In this cell line, a temperature-sensitive SV40 large T-cell antigen (tsA58 Tag) is controlled by a $\gamma$-interferon inducible $\mathrm{H}-2 \mathrm{~Kb}$ promoter. To induce proliferation, the cells were grown on type I collagen-coated plastic culture bottles (BD Biosciences, Bedford, MA, USA), at $33^{\circ} \mathrm{C}$ in RPMI-1640 culture medium (Gibco-BRL, Gaithersburg, MD, USA) supplemented with $10 \%$ fetal bovine serum (FBS; Gibco-BRL), $100 \mathrm{U} / \mathrm{ml}$ penicillin and $100 \mathrm{mg} / \mathrm{ml}$ streptomycin (both from Invitrogen, Carlsbad, CA, USA), to which recombinant mouse $\gamma$-interferon $10 \mathrm{U} / \mathrm{ml}$ (PeproTech, Rocky Hill, NJ, USA) was added (growth-permissive conditions). To induce quiescence and phenotype differentiation, the podocytes were grown at $37^{\circ} \mathrm{C}$ and deprived of $\gamma$-interferon (growth-restrictive conditions) in RPMI-1640 supplemented with $10 \%$ FBS, and 1-2 drops of penicillin and streptomycin. The culture medium was replaced every three days. When the cells grew slowly, the cell volume increased significantly, and pedicels (foot processes) extended from the podocytes, visualized under a phase contrast microscope (Olympus, Tokyo, Japan), indicating that the podocytes had differentiated. When the podocytes reached $75-85 \%$ confluence under growth-restrictive conditions, they were washed once with serum-free RPMI-1640 medium, and then growth-arrest was induced in serum-free RPMI-1640 medium for $24 \mathrm{~h}$ to synchronize the cell growth. The podocytes were then ready for the following experiments.
Cell stimulation. Differentiated mouse podocytes were stimulated with normal glucose [NG; 1 g/l D-glucose (Sigma, St. Louis, MO, USA)] or HG (4.5g/1 D-glucose). A third group of podocytes was exposed to $1 \mathrm{~g} / 1 \mathrm{D}$-glucose plus $24.4 \mathrm{mM}$ mannitol (Sigma) as an osmotic control (M). Cells in each group were collected at 12, 24, 48 and $72 \mathrm{~h}$ for analyses.

TUNEL assay. Apoptotic cells were identified by the TUNEL technique (Promega, Madison, WI, USA), according to the manufacturer's instructions. Differentiated mouse podocytes were plated on cover slides in six-well plates. Following stimulation with the indicated treatments, the cells were washed with $0.01 \mathrm{M}$ phosphate-buffered saline (PBS) and fixed with $4 \%$ paraformaldehyde at room temperature for $30 \mathrm{~min}$. The cells were then treated with proteinase $\mathrm{K}$ at room temperature and incubated in terminal deoxynucleotidyl transferase (TdT) buffer for $1 \mathrm{~h}$ at $37^{\circ} \mathrm{C}$. Endogenous peroxidase activity was inhibited using $0.3 \% \mathrm{H}_{2} \mathrm{O}_{2}$. The cells were incubated with horseradish peroxidase (HRP)-conjugated streptavidin at room temperature for $5 \mathrm{~min}$. DAB working solution was added and the cells were counterstained with hematoxylin. Negative control cells were incubated with the labeling solution (without TdT) instead of the TdT reaction solution. Apoptotic cell nuclei appeared as dark brown/black under an E600 light microscope (Nikon, Tokyo, Japan). For the quantification of TUNEL-positive (apoptotic) cells, a minimum of 200 cells were counted at six random fields (x10) per group, and the percentage of the positively-labeled cells was calculated.

Analysis of apoptosis by flow cytometry. The differentiated mouse podocytes were synchronized and stimulated with the indicated treatments for 12, 24, 48 and $72 \mathrm{~h}$. The cells were collected and washed twice with $4^{\circ} \mathrm{C}$ normal saline. The supernatant was removed following centrifugation at $1,000 \mathrm{rpm}$ for $5 \mathrm{~min}$. The cells were then fixed with $70 \%$ ethanol overnight. The cells were centrifuged (1,000 rpm, $5 \mathrm{~min})$, washed with normal saline, and then $1 \mathrm{ml}$ DNA dye [propidium iodide (PI) $50 \mu \mathrm{g} / \mathrm{ml}$, RNase $10 \mu \mathrm{g} / \mathrm{ml}$ and $1 \%$ Triton X-100; Sigma] was added. After staining for $30 \mathrm{~min}$ at $4^{\circ} \mathrm{C}$, the cells were analyzed by flow cytometry (Epics-XL II; Beckman Coulter, Brea, CA, USA). Expo32ADC software was used for analysis: a hypo-diploid peak prior to the peak of the diploid cells was considered as the apoptotic cell population. The apoptotic rate was calculated according to the distribution histogram of the hypo-diploid population.

Immunocytochemistry. PV-9000 two-step immunohistochemical reagent (Beijing Zhongshan Golden Bridge Biotechnology Co., Ltd., China) was used to assess GRP78, CHOP/GADD153 and caspase-12 expression. In brief, the podocytes were plated on cover slides in six-well plates. Following stimulation with the indicated treatments, the cells were fixed with $4 \%$ paraformaldehyde at room temperature for $15 \mathrm{~min}$. Following pre-treatment with $0.3 \%$ Triton $\mathrm{X}-100$ for $20 \mathrm{~min}$ at $37^{\circ} \mathrm{C}$, the cells were blocked with goat serum for $30 \mathrm{~min}$ at $37^{\circ} \mathrm{C}$. The cells were then incubated with rabbit anti-GRP78 polyclonal antibody (1:100 dilution; NeoMarkers Inc., Fremont, CA, USA), rabbit anti-CHOP/GADD153 polyclonal antibody (1:100 dilution; Santa Cruz Biotechnology Inc., Santa Cruz, CA, USA) and rabbit anti-caspase-12 polyclonal antibody 
Table I. PCR primer sequences.

\begin{tabular}{|c|c|c|c|}
\hline Gene & Primer sequences & $\mathrm{T}_{\mathrm{m}}\left({ }^{\circ} \mathrm{C}\right)$ & Product size (bp) \\
\hline GRP78 & $\begin{array}{l}\text { F: 5'-AACCCAGATGAGGCTGTAGCA-3' } \\
\text { R: 5'-ACATCAAGCAGAACCAGGTCAC-3' }\end{array}$ & 55 & 91 \\
\hline CHOP/GADD153 & $\begin{array}{l}\text { F: 5'-CCAGCAGAGGTCACAAGCAC-3' } \\
\text { R: 5'-CGCACTGACCACTCTGTTTC-3' }\end{array}$ & 42 & 126 \\
\hline Caspase-12 & $\begin{array}{l}\text { F: 5'-CACTGCTGATACAGATGAGG-3' } \\
\text { R: 5'-CCACTCTTGCCTACCTTCC-3' }\end{array}$ & 56 & 138 \\
\hline 18S rRNA & $\begin{array}{l}\text { F: 5'-ACACGGACAGGATTGACAGA-3' } \\
\text { R: 5'-GGACATCTAAGGGCATCACA-3' }\end{array}$ & 56 & 238 \\
\hline
\end{tabular}

F, forward primer; $\mathrm{R}$, reverse primer; $\mathrm{T}_{\mathrm{m}}$, melting temperature; PCR, polymerase chain reaction; GRP78, glucose-regulated protein 78; CHOP/ GADD153, CCAAT/enhancer-binding protein (C/EBP) homologous protein (also known as GADD153).

(1:1,000 dilution; Abcam, Cambridge, MA, USA) overnight at $4^{\circ} \mathrm{C}$. Following three washes with PBS, the cells were incubated with a polymer helper and polyperoxidase-anti-rabbit IgG (Beijing Zhongshan Golden Bridge Biotechnology Co., Ltd., Beijing, China) at $37^{\circ} \mathrm{C}$ for $30 \mathrm{~min}$, and the cells were then stained with diaminobenzidine. A negative control was created by replacing the primary antibody with PBS buffer. The cells were counterstained with hematoxylin. The entire stained areas were scanned at x100 magnification using an E600 light microscope.

Reverse transcription polymerase chain reaction (RT-PCR). Total RNA was extracted from each group using TRIzol reagent (Invitrogen). RNA purity was estimated by calculating the 260/280 $\mathrm{nm}$ absorbance and reverse transcribed into cDNA using an RT-PCR kit (Promega), according to the manufacturers' instructions. Relative levels of target gene mRNA expression normalized to $18 \mathrm{~S}$ rRNA were determined by the PCR system using the cDNA as a template and specific primers synthesized by Beijing AuGCT Biotechnology Co. Ltd., Beijing, China (Table I). PCR reactions were performed in duplicate at $95^{\circ} \mathrm{C}$ for $5 \mathrm{~min}$ and subjected to 36 cycles of $94^{\circ} \mathrm{C}$ for $1 \mathrm{~min}, 56-59^{\circ} \mathrm{C}$ for $45 \mathrm{sec}$ and $72^{\circ} \mathrm{C}$ for $1 \mathrm{~min}$, followed by $72^{\circ} \mathrm{C}$ for $10 \mathrm{~min}$. PCR products were separated by $2 \%$ agarose gel electrophoresis with ethidium bromide staining and analyzed using a GDS-8000 Bioimaging system (UVP Inc., Upland, CA, USA) and LabWorks 4.5 software (UVP Inc.).

Western blot analysis. The cells were harvested and homogenized on ice-cold homogenization buffer $(10 \mathrm{mM}$ Tris- $\mathrm{HCl}$, pH 7.4, 1.5 mM EDTA, pH 8.0 and $100 \mathrm{mg} / 1$ phenylmethylsulfonyl fluoride; Sigma), followed by centrifugation at $20,000 \mathrm{x}$ g for $20 \mathrm{~min}$ at $4^{\circ} \mathrm{C}$. Supernatants were collected for characterizing the relative levels of protein expression by western blot analysis. In addition, nuclear proteins in some cells were extracted using nuclear and cytoplasmic protein extraction kits (KeyGen Biotech, Nanjing, China), according to the manufacturer's instructions, followed by the quantification of protein concentrations using Coomassie brilliant blue.

Total cellular protein $(100 \mu \mathrm{g} /$ lane $)$ or nuclear protein (60 $\mu \mathrm{g} /$ lane) were separated by $10 \%$ SDS-PAGE and trans- ferred onto polyvinylidene fluoride (PVDF) membranes (Millipore Corp., Billerica, MA, USA). After being blocked with 5\% non-fat dry milk in Tris-buffered saline/Tween-20 (TBST) buffer for $2 \mathrm{~h}$, the membranes were incubated overnight at $4^{\circ} \mathrm{C}$ with rabbit polyclonal antibodies against GRP78 (1:1,000 dilution), caspase-12 (1:1,000) and $\beta$-actin $(1: 1,000$; Biosynthesis Biotechnology Co., Ltd., Beijing, China), rabbit polyclonal antibodies against CHOP/GADD153 (1:500) and histone H1 (1:500; Boster Biotechnology, Wuhan, China). Subsequently, the membranes were incubated with horseradish peroxidase-conjugated goat anti-rabbit IgG (1:5,000; Amersham Biosciences, Piscataway, NJ, USA) at $37^{\circ} \mathrm{C}$ for $2 \mathrm{~h}$. After TBST washing, enhanced chemiluminescence (ECL) reagent (Tiangen Biotech Co., Ltd., Beijing, China) was added to the membranes. Western blot bands were read for integrated optical density (IOD) and quantified using LabWorks 4.5 software (UVP).

Statistical analysis. Data were processed using SPSS 13.0 software (SPSS Inc., Chicago, IL, USA). The results are presented as the means \pm standard deviation (SD). Statistical analysis was performed using one-way ANOVA with the least significant difference (LSD) t-test for post hoc analysis. Correlation analysis was performed using the Spearman's test. A value of $\mathrm{P}<0.05$ was considered to indicate a statistically significant difference.

\section{Results}

$H G$ induces apoptosis of differentiated mouse podocytes. To determine the effects of HG on podocyte apoptosis, the podocytes were cultured in RPMI-1640 medium containing $1 \mathrm{~g} / 1 \mathrm{D}$-glucose (NG, control group), $1 \mathrm{~g} / 1 \mathrm{D}$-glucose plus $24.4 \mathrm{mM}$ mannitol (M group, osmotic control group) and $4.5 \mathrm{~g} / \mathrm{l} \mathrm{D}$-glucose (HG, experimental group) for 12, 24, 48 and $72 \mathrm{~h}$. Apoptotic rates were determined by TUNEL assay and flow cytometry (PI staining). Fig. 1A and B shows that compared with the control groups, podocyte apoptotic rates in the HG group were increased at $48 \mathrm{~h}$, and even more so at $72 \mathrm{~h}$. Indeed, $5.8 \pm 2.1 \%$ apoptotic cells in the NG group and $6.7 \pm 1.2 \%$ apoptotic cells in the $\mathrm{M}$ group, compared with $16.3 \pm 2.1$ and $36.3 \pm 2.6 \%$ apoptotic cells in the HG group at 48 


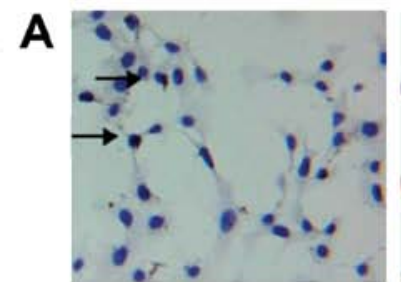

$12 \mathrm{~h}$

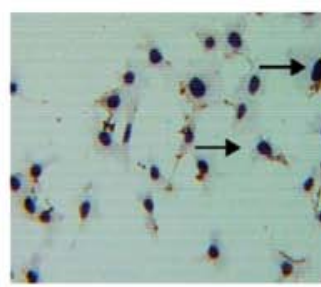

$24 \mathrm{~h}$

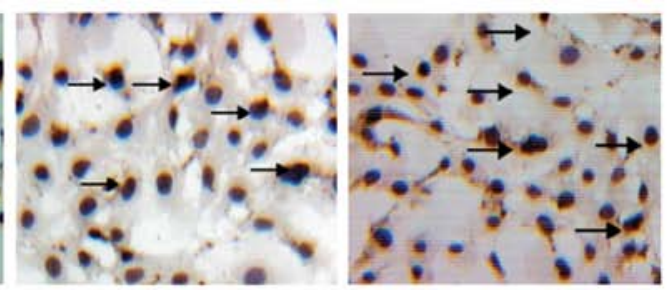

$48 h$
$72 \mathrm{~h}$

HG
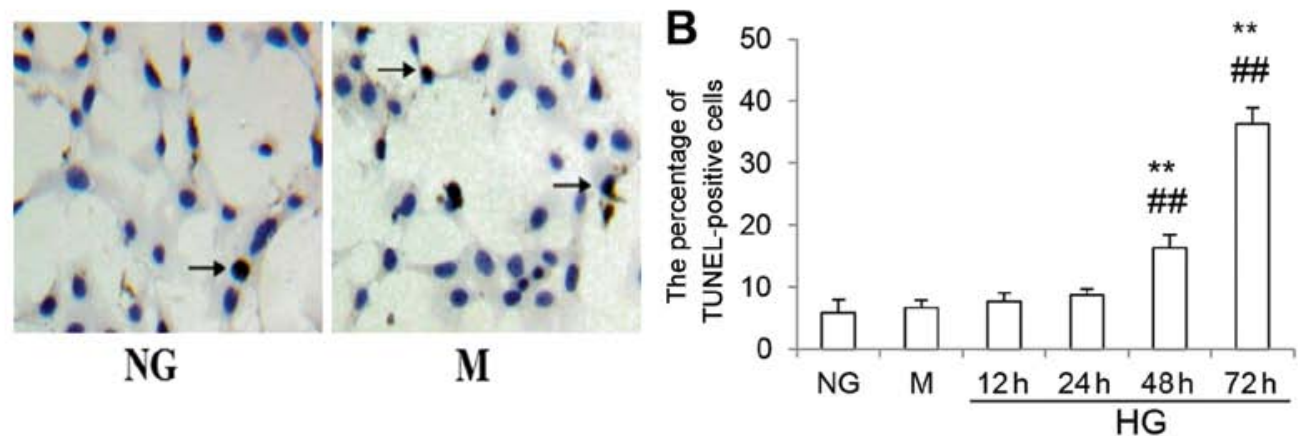

C
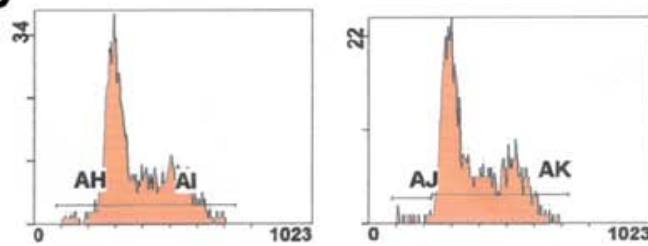

$12 \mathrm{~h}$

$24 \mathrm{~h}$

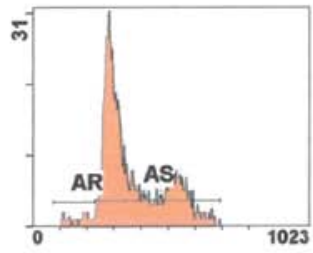

$48 \mathrm{~h}$

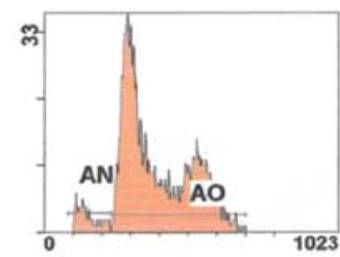

$72 \mathrm{~h}$

\section{HG}

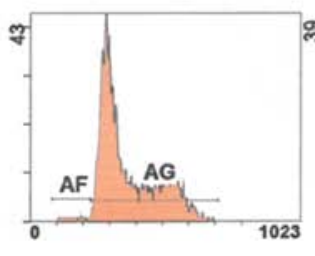

NG

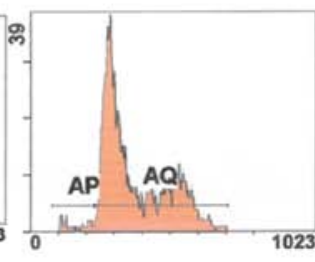

M

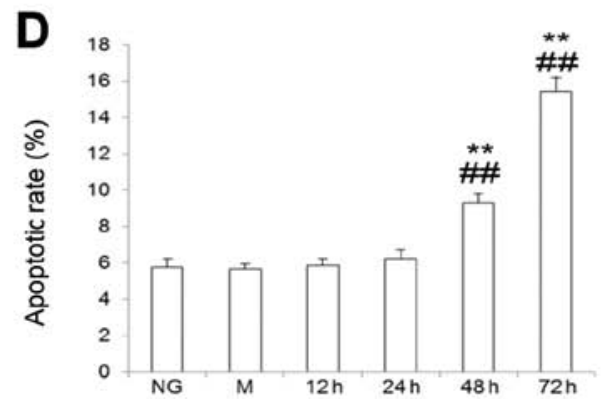

Figure 1. Effects of high glucose on differentiated mouse podocyte apoptosis. Differentiated mouse podocytes were incubated with $1 \mathrm{~g} / \mathrm{l} \mathrm{D}$-glucose [normal glucose group (NG) group], $1 \mathrm{~g} / 1 \mathrm{D}$-glucose plus $24.4 \mathrm{mM}$ mannitol (M group, osmotic control) and $4.5 \mathrm{~g} / 1 \mathrm{D}$-glucose [high glucose group (HG) group] for 12, 24, 48 and $72 \mathrm{~h}$. (A) Apoptosis in podocytes was detected using the TUNEL assay. Arrows indicate TUNEL-positive (apoptotic) cells (magnification, x100). (B) For quantification of TUNEL-positive (apoptotic) cells, a minimum of 200 cells was counted at six random fields (magnification, x100) per group, and the percentage of the positively-labeled cells was calculated. (C) Apoptosis was determined by propidium iodide (PI) staining using flow cytometry. (D) The results of flow cytometry were expressed as the percentage (\%) apoptotic rate. Apoptotic rate was calculated according to the distribution histogram of the hypo-diploid population. Data are presented as the means \pm standard deviation (SD). ${ }^{* *} \mathrm{P}<0.01$ vs. NG group; ${ }^{\# \#} \mathrm{P}<0.01$ vs. M group.

and $72 \mathrm{~h}$ (all $\mathrm{P}<0.01)$, respectively, were detected by TUNEL assay. The results were consistent with the results from flow cytometric analysis (Fig. 1C and D). As expected, mannitol had no effect on podocyte apoptosis as assessed using these two methods.

$H G$ stimulation upregulates the expression of the ER chaperone, GRP78, in differentiated mouse podocytes. GRP78, an important molecular chaperone localized in the ER, was used as an indicator of ERS (16). As can be seen in Fig. 2C, immunocytochemistry revealed that GRP78 was abundantly expressed in the cells in the HG group. By contrast, the cells in the NG and $\mathbf{M}$ groups showed only a modest or weak GRP78 signal. Western blot analysis revealed that GRP78 expression was significantly increased at 12 and $24 \mathrm{~h}$ (both $\mathrm{P}<0.05$ ), and then decreased at $48 \mathrm{~h}$, approximately returning to the control levels by $72 \mathrm{~h}$ (Fig. 2B). Furthermore, RT-PCR analysis revealed the same trend in GRP78 mRNA levels. However, GRP78 mRNA levels remained higher at $72 \mathrm{~h}(\mathrm{P}<0.05)$ (Fig. 2A). These findings suggested that UPR was induced and that ERS was activated in the differentiated mouse podocytes exposed to HG.

HG stimulation induces the activation of the CHOP/GADD153dependent apoptotic pathway in differentiated mouse 

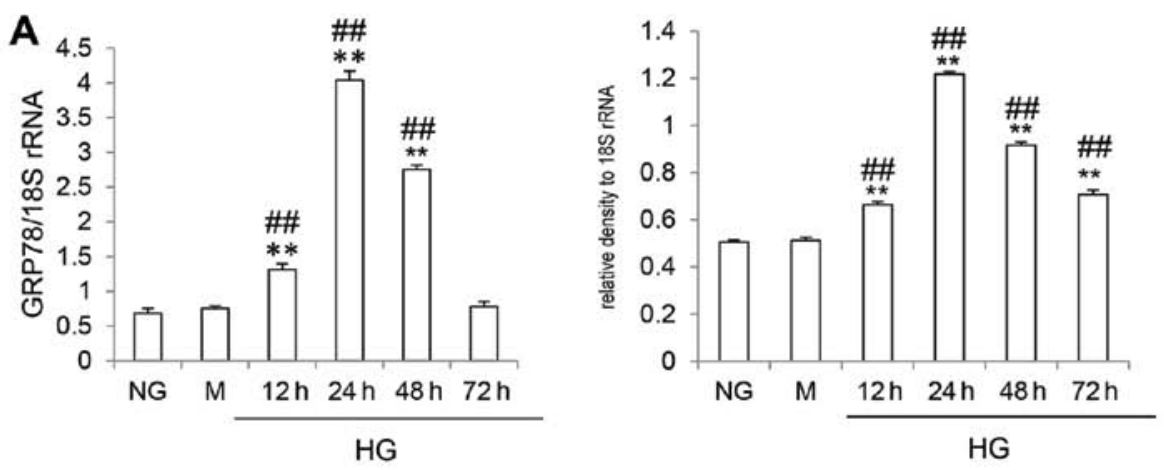

B
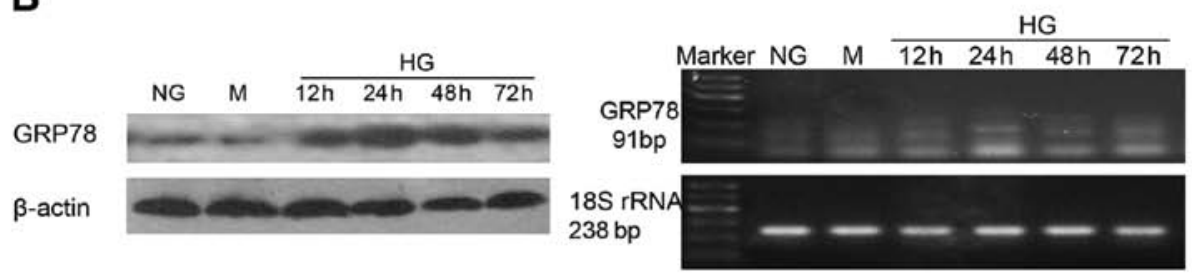

C

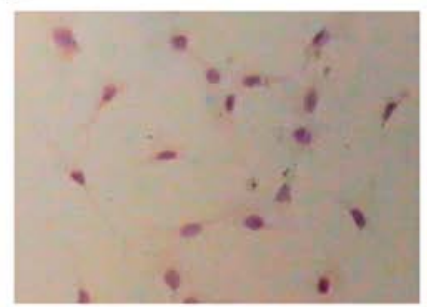

NG

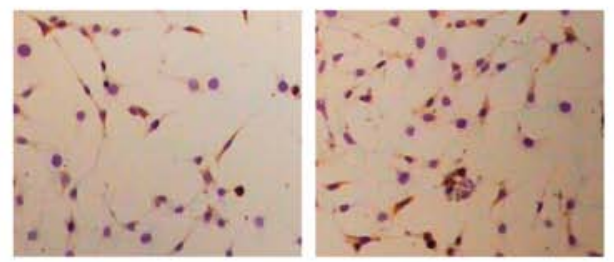

$12 \mathrm{~h}$

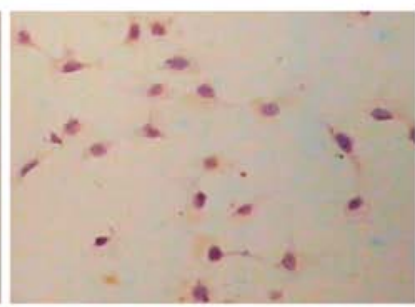

M

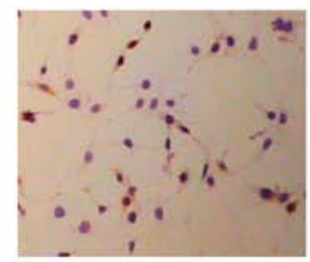

$48 \mathrm{~h}$



$72 \mathrm{~h}$

HG

Figure 2. Effects of high glucose (HG) on GRP78 mRNA and protein expression on differentiated mouse podocytes. Podocytes were incubated with $1 \mathrm{~g} / 1$ D-glucose [normal glucose group (NG) group], $1 \mathrm{~g} / 1 \mathrm{D}$-glucose plus $24.4 \mathrm{mM}$ mannitol (M group, osmotic control) and $4.5 \mathrm{~g} / 1 \mathrm{D}$-glucose (HG group) for 12 , 24, 48 and $72 \mathrm{~h}$. (A) GRP78 mRNA expression was analyzed by RT-PCR, mRNA expression was normalized to 18S rRNA. (B) GRP78 protein expression was determined by western blot analysis. Protein expression was normalized to $\beta$-actin. (C) GRP78-positive expression was detected by immunocytochemistry (magnification, $\mathrm{x} 100$ ). Data are presented as the means \pm standard deviation (SD). ${ }^{* *} \mathrm{P}<0.01 \mathrm{vs.} \mathrm{NG}$ group; ${ }^{\# \#} \mathrm{P}<0.01$ vs. $\mathrm{M}$ group.

podocytes. CHOP/GADD153 is a nuclear protein forming stable heterodimers with $\mathrm{C} / \mathrm{EBP}$ family members $(8,17)$. As illustrated in Fig. 3C, it was detectable at low levels in the cells in the NG and M groups, whereas in the cells in the $\mathrm{HG}$ group, CHOP/GADD153 expression was increased as detected by immunocytochemistry. Western blot analysis revealed that CHOP/GADD153 expression was increased at $24 \mathrm{~h}$, reaching a peak at $48 \mathrm{~h}$, and then decreasing at $72 \mathrm{~h}$, but without returning to the control levels (all $\mathrm{P}<0.05)$ (Fig. 3B). RT-PCR analysis revealed that $\mathrm{CHOP} / \mathrm{GADD} 153 \mathrm{mRNA}$ levels were increased at $12 \mathrm{~h}$, also reaching a peak at $48 \mathrm{~h}$, and then decreasing at $72 \mathrm{~h}$, but without returning to the control levels (all $\mathrm{P}<0.05$ ) (Fig. 3A). These data suggested that the CHOP/GADD153- dependent apoptotic pathway was activated by HG stimulation in the differentiated mouse podocytes.

HG stimulation activates the caspase-12-dependent apoptotic pathway in the differentiated mouse podocytes. Caspase-12 is exclusively located in the ER. It is ubiquitously and constitutively expressed, but unlike other caspases, caspase-12 is specifically activated by ERS (18). As shown in Fig. 4C, immunocytochemistry revealed that caspase-12 expression was increased in the cells in the HG group compared with the control cells (NG and M group cells). Western blot analysis revealed that $\mathrm{HG}$ stimulation increased caspase-12 protein levels in a time-dependent manner (all $\mathrm{P}<0.05$ ) (Fig. 4B). HG 

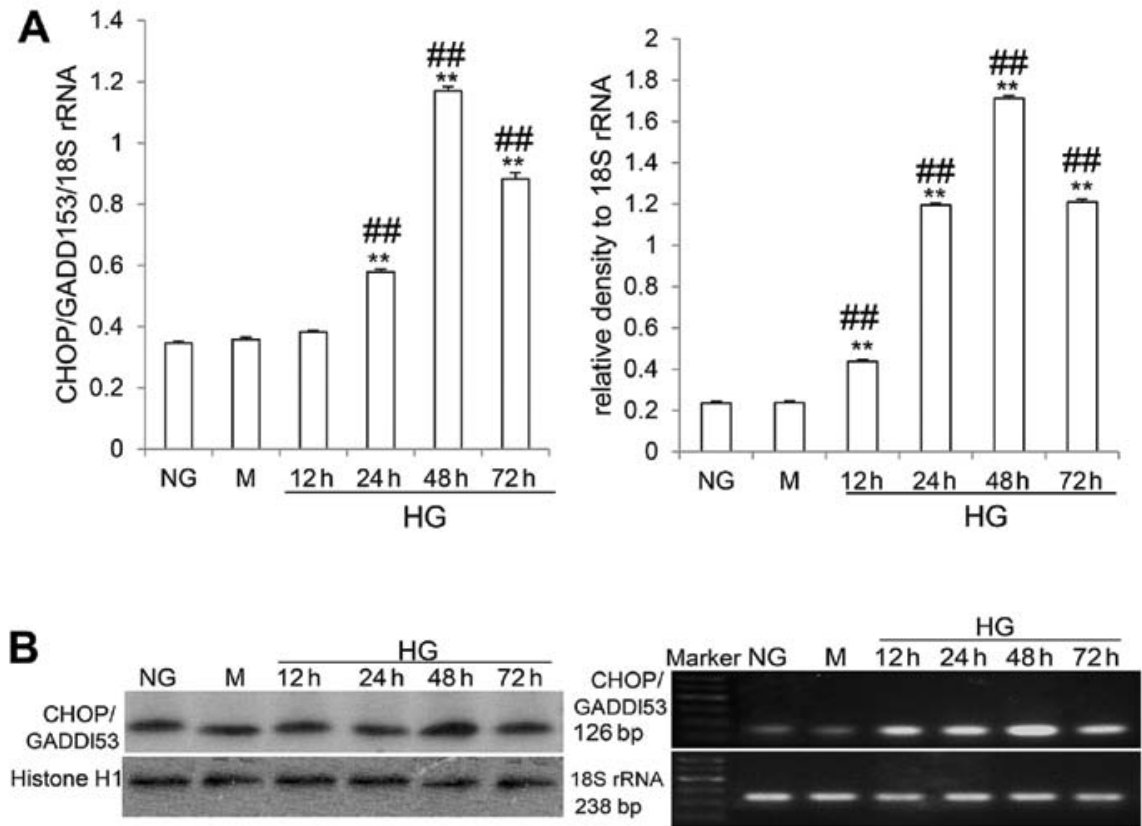

\section{C}
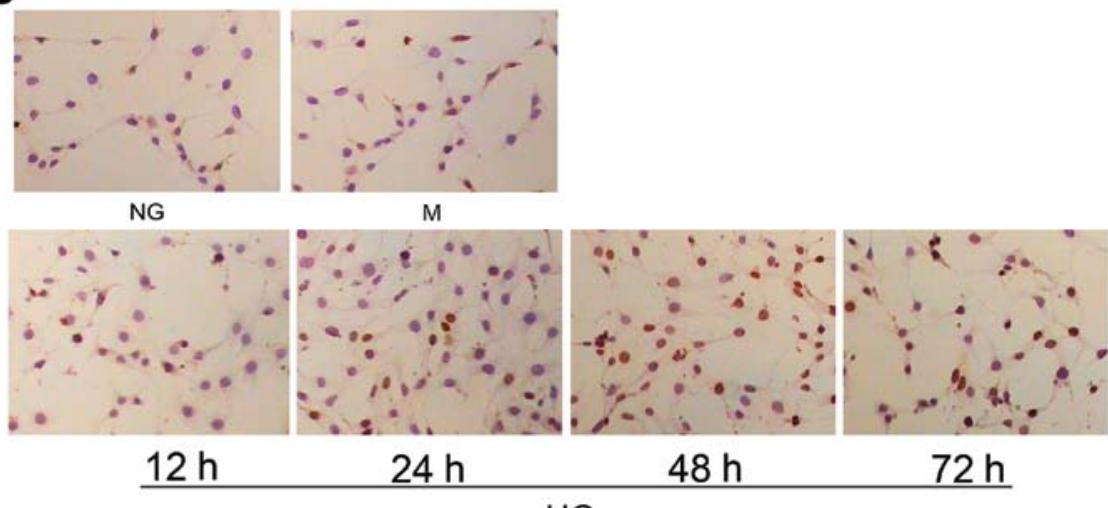

HG

Figure 3. Effects of high glucose (HG) on CHOP/GADD153 mRNA and protein expression on differentiated mouse podocytes. Podocytes were incubated with $1 \mathrm{~g} / 1 \mathrm{D}$-glucose [normal glucose group (NG) group], $1 \mathrm{~g} / 1 \mathrm{D}$-glucose plus $24.4 \mathrm{mM}$ mannitol (M group, osmotic control) and $4.5 \mathrm{~g} / 1 \mathrm{D}$-glucose (HG group) for 12, 24, 48 and $72 \mathrm{~h}$. (A) CHOP/GADD153 mRNA expression was analyzed by RT-PCR, and the mRNA expression was normalized to $18 \mathrm{~S}$ rRNA. (B) CHOP/GADD153 protein expression was determined by western blot analysis. Protein expression was normalized to $\beta$-actin. (C) CHOP/GADD153-positive expression was detected by immunocytochemistry (magnification, $\mathrm{x} 100$ ). Data are presented as the means \pm standard deviation (SD). ${ }^{* *} \mathrm{P}<0.01 \mathrm{vs.} \mathrm{NG}$ group; ${ }^{\# \#} \mathrm{P}<0.01$ vs. M group.

stimulation also increased the mRNA levels of caspase-12 in a time-dependent manner (all $\mathrm{P}<0.05)$ (Fig. 4A). These data indicated that HG stimulation activated the caspase-12-dependent apoptosis pathway in the differentiated mouse podocytes.

Correlation between caspase-12 and CHOP/GADD153 protein expression and apoptosis induced by HG. Spearman's correlation analysis revealed that caspase-12 and CHOP/GADD153 positively correlated with the apoptotic rate $(\mathrm{r}=0.915, \mathrm{P}<0.01$ and $\mathrm{r}=0.639, \mathrm{P}<0.01$ ).

\section{Discussion}

Podocytes, a type of glomerular epithelial cell, are unique, highly specialized and terminally differentiated cells (6). The loss of podocytes leads to the stripping of areas of the glomerular basement membrane, which contributes to impaired renal function, as is evident by proteinuria and the development of glomerulosclerosis (7). It is generally accepted that apoptosis is a major cause of podocytes loss, occurring early in the development of DN and closely correlating with its progression $(19,20)$.

ERS is generally present under physiological and pathological conditions, and is an important inducer of cell apoptosis $(15,16)$. A growing number of studies have demonstrated that ERS plays a key role in the pathogenesis of several renal diseases, including DN (21). In the present study, we investigated the hypothesis that ERS is partly responsible for podocyte apoptosis induced by HG. We observed that some podocyte apoptosis was detected after 12 and $24 \mathrm{~h}$ in the cells exposed to HG and the control cells, but without significant 

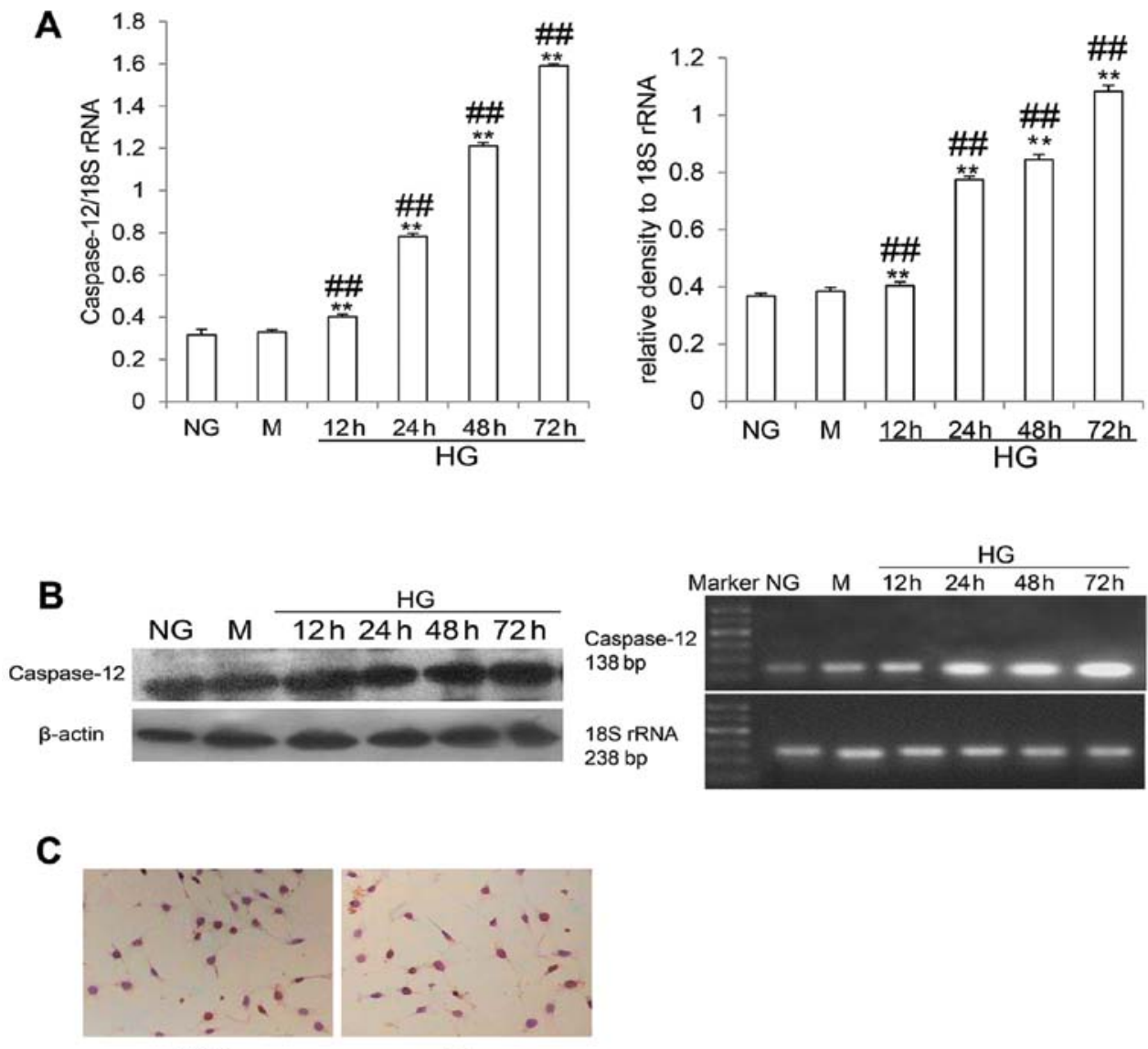

NG

M

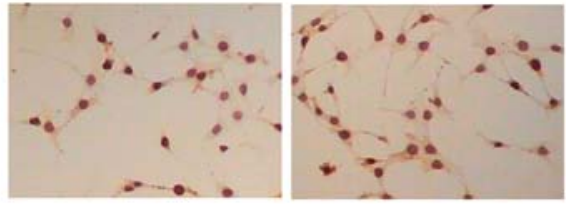

$12 \mathrm{~h}$

$24 \mathrm{~h}$



$48 h$ $72 h$

HG

Figure 4. Effects of high glucose (HG) on caspase-12 mRNA and protein expression on differentiated mouse podocytes. Podocytes were incubated with $1 \mathrm{~g} / 1$ D-glucose [normal glucose group (NG) group], $1 \mathrm{~g} / \mathrm{l} \mathrm{D}$-glucose plus $24.4 \mathrm{mM}$ mannitol (M group, osmotic control) and $4.5 \mathrm{~g} / 1 \mathrm{D}$-glucose (HG group) for 12 , 24, 48 and 72 h. (A) Caspase-12 mRNA expression was analyzed by RT-PCR, and the mRNA expression was normalized to $18 \mathrm{~S}$ rRNA. (B) Caspase-12 protein expression was determined by western blot analysis. Protein expression was normalized to $\beta$-actin. (C) Caspase-12-positive expression was detected by immunocytochemistry (magnification, $x 100$ ). Data are presented as the means \pm standard deviation (SD). ${ }^{* *} \mathrm{P}<0.01$ vs. NG group; ${ }^{\# *} \mathrm{P}<0.01$ vs. $\mathrm{M}$ group.

differences between these two groups. However, the number of apoptotic cells markedly increased with the increasing exposure time to HG.

The levels of GRP78, a key UPR modulator (15), were increased in the cells exposed to $\mathrm{HG}$ at 12 and $24 \mathrm{~h}$, and decreased by $72 \mathrm{~h}$. These results suggested that UPR was induced and that ERS was activated when the podocytes were exposed to HG. Based on current knowledge, the function of UPR is to adapt to the changing environment and to re-establish a normal ER function (15). However, our data indicated that this protective effect of the UPR lasted only for a short time, even if the stress was persistent. These results suggest that this protective mechanism is eventually overpowered and that apoptosis ensues.

CHOP/GADD153 is a nuclear protein that forms stable heterodimers with C/EBP family members (22). It is barely detectable under normal physiological conditions, but it is strongly induced in response to ERS (23). The overexpression of CHOP/GADD153 and the microinjection of CHOP/ GADD153 protein have been reported to lead to cell cycle arrest and/or apoptosis (24-27). The overexpression of GRP78 (also known as BiP) may attenuate the induction of $\mathrm{CHOP} /$ GADD153 in ERS and may reduce ERS-induced apoptosis. Our results revealed that just as GRP78 expression began to weaken at $48 \mathrm{~h}, \mathrm{CHOP} / \mathrm{GADD} 153$ expression reached its peak. Furthermore, CHOP/GADD153 expression correlated with the apoptotic rate in cells exposed to HG.

Caspase-12 is exclusively located in the ER (18). It is ubiquitously and constitutively expressed, but unlike other caspases, caspase-12 is specifically activated by insults inducing ERS and not by other death stimuli (29). Following its activation, it can 
directly process downstream caspases in the cytosol, mainly caspase-9 and -3 (30). Our results demonstrated that caspase-12 expression gradually increased with time in response to $\mathrm{HG}$, and that its levels correlated with the apoptotic rate in cells exposed to $\mathrm{HG}$.

The results from the present study demonstrated that hyperglycemia induced ERS in podocytes, and that this stress gradually exceeded the capacity of different protective mechanisms, including GRP78 response. CHOP/GADD153 and caspase-12 were activated according to different patterns, suggesting that these mechanisms contribute differently to podocyte apoptosis. Nevertheless, these mechanisms partially contribute to the pathogenesis of DN.

In conclusion, hyperglycemia induced apoptosis partly through ERS in differentiated mouse podocytes, and this may contribute to the pathogenesis of DN. HG-stimulated podocytes undergo ERS, which presumably is an adaptive, protective UPR reaction for cell survival; however, this protective effect was short-lived, since continued exposure to HG eventually overpowered this effect and led to apoptosis. These results indicate that novel (previously unknown) mechanisms involved in DN may be targeted by novel therapeutic interventions.

\section{Acknowledgements}

This study was supported by grants from the National Natural Science Foundation of China (nos. 81000301 and 81100517) and the Technology Bureau of Handan (no. 1223108149).

\section{References}

1. Pavkov ME, Knowler WC, Bennett PH, Looker HC, Krakoff J and Nelson RG: Increasing incidence of proteinuria and declining incidence of end-stage renal disease in diabetic Pima Indians. Kidney Int 70: 1840-1846, 2006

2. Cowie CC, Port FK, Wolfe RA, Savage PJ, Moll PP and Hawthorne VM: Disparities in incidence of diabetic end-stage renal disease according to race and type of diabetes. $N$ Engl $\mathbf{J}$ Med 321: 1074-1079, 1989.

3. Adler S: Diabetic nephropathy: linking histology, cell biology, and genetics. Kidney Int 66: 2095-2106, 2004.

4. Mason RM and Wahab NA: Extracellular matrix metabolism in diabetic nephropathy. J Am Soc Nephrol 14: 1358-1373, 2003.

5. Shankland SJ: The podocyte's response to injury: role in proteinuria and glomerulosclerosis. Kidney Int 69: 2131-2147, 2006.

6. Mundel P and Shankland SJ: Podocyte biology and response to injury. J Am Soc Nephrol 13: 3005-3015, 2002.

7. Kriz W, Gretz N and Lemley KV: Progression of glomerular diseases: is the podocyte the culprit? Kidney Int 54: 687-697, 1998

8. Xu C, Bailly-Maitre B and Reed JC: Endoplasmic reticulum stress: cell life and death decisions. J Clin Invest 115: 2656-2664, 2005.

9. Marciniak SJ, Yun CY, Oyadomari S, et al: CHOP induces death by promoting protein synthesis and oxidation in the stressed endoplasmic reticulum. Genes Dev 18: 3066-3077, 2004.

10. Susztak K, Raff AC, Schiffer M and Böttinger EP: Glucoseinduced reactive oxygen species cause apoptosis of podocytes and podocyte depletion at the onset of diabetic nephropathy. Diabetes 55: 225-233, 2006.
11. Siu B, Saha J, Smoyer WE, Sullivan KA and Brosius FC III: Reduction in podocyte density as a pathologic feature in early diabetic nephropathy in rodents: prevention by lipoic acid treatment. BMC Nephrol 7: 6, 2006.

12. King GL and Loeken MR: Hyperglycemia-induced oxidative stress in diabetic complications. Histochem Cell Biol 122: 333-338, 2004.

13. Zhang W, Feng D, Li Y, Iida K, McGrath B and Cavener DR: PERK EIF2AK3 control of pancreatic beta cell differentiation and proliferation is required for postnatal glucose homeostasis. Cell Metab 4: 491-497, 2006.

14. Laybutt DR, Preston AM, Akerfeldt MC, et al: Endoplasmic reticulum stress contributes to beta cell apoptosis in type 2 diabetes. Diabetologia 50: 752-763, 2007.

15. Ron D and Walter P: Signal integration in the endoplasmic reticulum unfolded protein response. Nat Rev Mol Cell Biol 8: 519-529, 2007.

16. Rao RV, Peel A, Logvinova A, et al: Coupling endoplasmic reticulum stress to the cell death program: role of the ER chaperone GRP78. FEBS Lett 514: 122-128, 2002.

17. Zinszner H, Kuroda M, Wang X, et al: CHOP is implicated in programmed cell death in response to impaired function of the endoplasmic reticulum. Genes Dev 12: 982-995, 1998.

18. Szegezdi E, Logue SE, Gorman AM and Samali A: Mediators of endoplasmic reticulum stress-induced apoptosis. EMBO Rep 7: 880-885, 2006.

19. Butt A and Riaz S: Study of protein profiling of human urine in diabetic hypertensive nephropathy versus normal healthy controls. Diabetes Technol Ther 12: 379-386, 2010.

20. Chen M, Felix K and Wang J: Immune regulation through mitochondrion-dependent dendritic cell death induced by T regulatory cells. J Immunol 187: 5684-5692, 2011.

21. Liu G, Sun Y, Li Z, et al: Apoptosis induced by endoplasmic reticulum stress involved in diabetic kidney disease. Biochem Biophys Res Commun 370: 651-656, 2008.

22. Ron D and Habener JF: CHOP, a novel developmentally regulated nuclear protein that dimerizes with transcription factors $\mathrm{C} / \mathrm{EBP}$ and LAP and functions as a dominant-negative inhibitor of gene transcription. Genes Dev 6: 439-453, 1992.

23. Wang XZ, Lawson B, Brewer JW, et al: Signals from the stressed endoplasmic reticulum induce C/EBP-homologous protein (CHOP/GADD153). Mol Cell Biol 16: 4273-4280, 1996.

24. Matsumoto M, Minami M, Takeda K, Sakao Y and Akira S: Ectopic expression of CHOP (GADD153) induces apoptosis in M1 myeloblastic leukemia cells. FEBS Lett 395: 143-147, 1996.

25. Maytin EV, Ubeda M, Lin JC and Habener JF: Stress-inducible transcription factor $\mathrm{CHOP} / \mathrm{gadd} 153$ induces apoptosis in mammalian cells via p38 kinase-dependent and -independent mechanisms. Exp Cell Res 267: 193-204, 2001.

26. Oyadomari S, Takeda K, Takiguchi M, et al: Nitric oxideinduced apoptosis in pancreatic beta cells is mediated by the endoplasmic reticulum stress pathway. Proc Natl Acad Sci USA 98: 10845-10850, 2001.

27. Gotoh T, Oyadomari S, Mori K and Mori M: Nitric oxideinduced apoptosis in RAW 264.7 macrophages is mediated by endoplasmic reticulum stress pathway involving ATF6 and CHOP. J Biol Chem 277: 12343-12350, 2002.

28. Oyadomari S and Mori M: Roles of CHOP/GADD153 in endoplasmic reticulum stress. Cell Death Differ 11: 381-389, 2004

29. Nakagawa T and Yuan J: Cross-talk between two cysteine protease families. Activation of caspase-12 by calpain in apoptosis. J Cell Biol 150: 887-894, 2000.

30. Liu H and Baliga R: Endoplasmic reticulum stress-associated caspase 12 mediates cisplatin-induced LLC-PK1 cell apoptosis. J Am Soc Nephrol 16: 1985-1992, 2005. 